\title{
Synthesis and Characterization of Poly[3]rotaxane through the Mizoroki-Heck Coupling Polymerization of Divinyl-functionalized [3]Rotaxane
}

\author{
By Takashi SATO and Toshikazu TAKATA*
}

Main chain-type poly[3]rotaxanes were synthesized according to the rotaxanation-polymerization protocol by the polymerization of a divinyl [3]rotaxane monomer through the Mizoroki-Heck coupling with a diiodoarene. [3]Rotaxane 5 consisting of two monovinyl dibenzo-24-crown-8-ether wheels (2) and sec-ammonium salt (3) as an axle component was synthesized in $86 \%$ yield by a typical urethane end-capping reaction of the axle terminal hydroxyl group with bis(4isocyanophenyl)methane in the presence of a catalytic amount of di- $n$-butyltin dilaurate. Quantitative $N$-acetylation of 5 yielded mono(vinylphenyl)-functionalized wheel-containing [3] rotaxane monomers $\mathbf{6}$. The mobility of the wheel components in [3] rotaxanes was evaluated by the two-dimention NOESY spectra of $\mathbf{5}$ and $\mathbf{6}$. The main-chain type poly[3]rotaxanes $\mathbf{8}$ were obtained in high yields by the Mizoroki-Heck-type polycondensation of $\mathbf{6}$ and diiodoarenes $\mathbf{7}$ in the presence of a palladium catalyst $\left(\mathrm{Pd}(\mathrm{OAc})_{2}\right)$. The structures of the polyrotaxanes were determined mainly by NMR and GPC, while the IR spectra showed that vinylene groups formed mainly took the trans configuration. Properties of the polyrotaxanes such as solubility and thermal stability were evaluated.

KEY WORDS: Main Chain-Type Rotaxane / [3]Rotaxane / Mizoroki-Heck Coupling / Poly(arylene-vinylene) /

Interlocked polymers, ${ }^{1-20}$ a novel class of polymers containing mechanical linkages consisting of wheels and/or axle components, are expected to display unique properties such as mechanical and rheological ones. Among polyrotaxanes as one of the interlocked polymers (Figure 1), both poly[2]rotaxane $^{21-33}$ and poly[3]rotaxane $e^{34,35}$ are specially unique as characterized by their structural feature that the polymer main chain has no successive covalent bond. The repeating units of these polymers are bound by mechanical bonds. Meanwhile, there is few report on polyrotaxane with the backbone consisting of mechanical bonds, i.e., topologically linked polymer backbone, in contrast to poly[2] catenanes. ${ }^{36-46}$

We previously reported the synthesis of poly[3]rotaxane utilizing the reversible cleavage-recombination process of the disulfide bond in the precense of a catalystic amount of thiol under thermodynamic control. ${ }^{34}$ Further, we have recently disclosed the synthesis of poly[2]rotaxane by the polymerization of a bifunctional rotaxane monomer via the Sonogashira coupling reaction, ${ }^{47}$ while a few poly[2]rotaxanes were synthesized by the thermaldynamic process. ${ }^{21,22,24-28}$ There are two possible ways accessing the main chain-type poly[3]rotaxane: one goes through the initial rotaxanation followed by the polymerization (Figure 2, route A), whereas the other undergoes the initial coupling of wheel followed by the rotaxanation to poly[3]rotaxane (Figure 2, route B), as shown in Figure 1. Our previous paper ${ }^{33}$ described the synthesis of a polyrotaxane by rotaxanation of ditopic wheel component utilizing the dynamic covalent chemistry of disulfide linkage, along Route B.

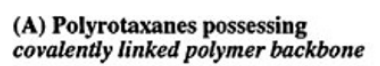

(B) Polyrotaxanes possessing covalently linked polymer backbone
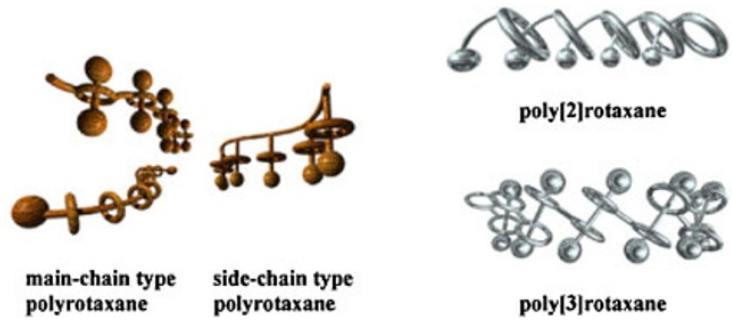

poly|2]rotaxane

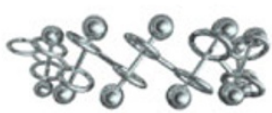

poly[3]rotaxane

Figure 1. Structures of typical polyrotaxanes.

In this paper, the synthesis of poly[3]rotaxanes by polycondensation via the Mizoroki-Heck coupling of diviynylfunctionalized [3] rotaxane and diiodoarenes, according to the rotaxanation-polymerization protocol along Route A.

\section{EXPERIMENTAL}

\section{Measurement}

${ }^{1} \mathrm{H}$ and ${ }^{13} \mathrm{C}$ NMR spectra were recorded on a JEOL GTX400 spectrometer using $\mathrm{CDCl}_{3}$ as the solvent with tetramethylsilane as the internal standard. FT-IR spectra were recorded on a JASCO FT-IR-230 spectrophotometer. Preparative GPC was carried out by a JAI HPLC LC-918 system equipped with two consecutive linear polystyrene gel columns (JASCO Megapack-Gel 201C, JAI JAIGEL-1H). Melting points were measured by a Stuart Scientific SMP3. Molecular 


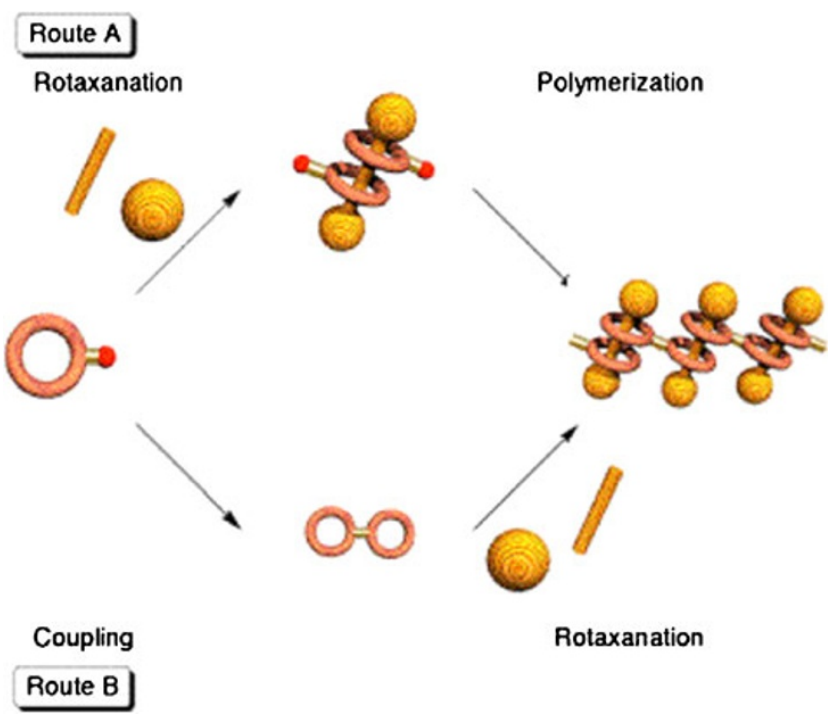

Figure 2. Synthetic strategy of poly[3]rotaxane.

weight and its distribution were estimated by GPC on a JASCO Gulliver system equipped with two consecutive linear polystyrene gel columns (Tosoh TSKgel G5000H $\mathrm{HL}_{\mathrm{X}}, \mathrm{G} 4000 \mathrm{H}_{\mathrm{XL}}$ ) at $30{ }^{\circ} \mathrm{C}$ (flow rate $0.085 \mathrm{~mL} / \mathrm{min}$ ) using polystyrene standards and chloroform as the eluent. The glass transition temperature $\left(T_{\mathrm{g}}\right)$ was determined with a Shimadzu DSC-60 instrument at a heating rate of $10{ }^{\circ} \mathrm{C} / \mathrm{min}$ under nitrogen atmosphere (flow rate $50 \mathrm{~mL} / \mathrm{min}$ ). The thermogravimetric analysis (TGA) was performed with a Shimadzu TGA-50 instrument at a heating rate of $10^{\circ} \mathrm{C} / \mathrm{min}$ under nitrogen atmosphere (flow rate $50 \mathrm{~mL} /$ min). High-resolution mass spectra were obtained by a ICP-MS (Seiko Instruments, SPQ-9000) at the Center for Advanced Materials Analysis, Tokyo Institute of Technology.

\section{Materials}

Tributylamine and $\mathrm{CH}_{2} \mathrm{Cl}_{2}$ were dried over calcium hydride and purified by distillation. Commercially available $\mathrm{NaH}$, acetic anhydride, triethylamine, $\mathrm{Pd}(\mathrm{OAc})_{2}$ (Wako Chemical Co., Ltd.), methyltriphenylphosphonim bromide, tri(o-tolyl)phosphane, dry DMF (Aldrich Chemical Co., Ltd.), and tributylphosphane (Tokyo Kasei Co., Ltd.) were used as received. Solvents other than $\mathrm{CH}_{2} \mathrm{Cl}_{2}$ were commercially available and used without further purification.

Monovinyl Dibenzo-24-crown-8-ether (Monovinyl DB24C8) (2). To a solution of 4-formylcatechol $(3.45 \mathrm{~g}, 25.0 \mathrm{mmol})$ and cesium carbonate $(81.4 \mathrm{~g}, 250 \mathrm{mmol})$ in dry THF $(500 \mathrm{~mL})$ was added ditosylate $\mathbf{1}(18.8 \mathrm{~g}, 27.5 \mathrm{mmol})$ dissolved in dry THF $(200 \mathrm{~mL})$. The mixture was refluxed for $3 \mathrm{~d}$. After cooling the mixture to room temperature, the mixture was extracted with chloroform. The chloroform layer was washed with $10 \%$ $\mathrm{K}_{2} \mathrm{CO}_{3}$ aq. and $\mathrm{H}_{2} \mathrm{O}$, separated, dried over anhydrous $\mathrm{MgSO}_{4}$, and evaporated to dryness. The residual product was purified by silica gel column chromatography $\left(\mathrm{CHCl}_{3} \rightarrow \mathrm{CHCl}_{3}\right.$ : $\mathrm{MeOH}(100 / 2))$ to give monoformyl DB24C8 $(8.46 \mathrm{~g}, 71 \%)$ as a white solid. ${ }^{1} \mathrm{H}$ NMR $\left(400 \mathrm{MHz}, \mathrm{CDCl}_{3}, 298 \mathrm{~K}\right): \delta 9.82(\mathrm{~s}$, 1H, CHO), 7.44-7.32 (m, 3H, ArH), 6.96-6.82 (m, 4H, ArH),
4.25-4.11 (m, 8H, crown- $\left.\mathrm{CH}_{2}\right), 3.98-3.89$ (m, 8H, crown$\mathrm{CH}_{2}$ ), 3.86-3.79 (m, $16 \mathrm{H}$, crown- $\left.\mathrm{CH}_{2}\right) \mathrm{ppm}$.

To a solution of methyltriphenylphosphonium bromide $(4.29 \mathrm{~g}, 12.0 \mathrm{mmol})$ in dry $\mathrm{CH}_{2} \mathrm{Cl}_{2}(60 \mathrm{~mL})$ was added $\mathrm{NaH}$ $(0.480 \mathrm{~g}, 12.0 \mathrm{mmol})$ and the mixture was stirred for $10 \mathrm{~min}$. To the mixture was slowly added a solution of monoformyl DB24C8 (1.91 g, $4.00 \mathrm{mmol}$ ) dissolved in dry $\mathrm{CH}_{2} \mathrm{Cl}_{2}(60 \mathrm{~mL})$ over a period of $1 \mathrm{~h}$. The resulting mixture was stirred for $14 \mathrm{~h}$ and subsequently quenched by the addition of $\mathrm{H}_{2} \mathrm{O}(30 \mathrm{~mL})$. The organic layer was separated, dried over anhydrous $\mathrm{MgSO}_{4}$, evaporated to dryness. The residual solid material was purified by silica gel column chromatography (eluent: $\mathrm{CH}_{2} \mathrm{Cl}_{2}$ and then $\left.\mathrm{CH}_{2} \mathrm{Cl}_{2}-\mathrm{MeOH}(25 / 1)\right)$ to give monovinyl DB24C8 2 (1.65 g, $87 \%)$ as a white solid. ${ }^{1} \mathrm{H}$ NMR $\left(400 \mathrm{MHz}, \mathrm{CDCl}_{3}, 298 \mathrm{~K}\right): \delta$ 6.95-6.72 (m, 7H, Ar-H), $6.61(\mathrm{~m}, 1 \mathrm{H}$, vinyl-CH), $5.57(\mathrm{~m}, 1 \mathrm{H}$, vinyl-H), $5.12(\mathrm{~m}, 1 \mathrm{H}$, vinyl-H), 4.18-4.10 (m, 8H, crown$\left.\mathrm{CH}_{2}\right)$, 3.93-3.87 (m, 8H, crown- $\left.\mathrm{CH}_{2}\right), 3.83-3.80(\mathrm{~m}, 8 \mathrm{H}$, crown- $\left.\mathrm{CH}_{2}\right)$ ppm; ${ }^{13} \mathrm{C} \mathrm{NMR}\left(100 \mathrm{MHz}, \mathrm{CDCl}_{3}, 298 \mathrm{~K}\right): \delta$ $148.78,148.72,136.20,131.04,121.24,119.78,113.99$, 113.57, 111.77, 111.38, 76.68, 71.03, 69.72, 69.69, 69.65, 69.29, 69.23, $69.20 \mathrm{ppm}$; IR (KBr): 3065 ( $v_{\mathrm{C}-\mathrm{H}}$ vinyl), 1125 $\left(v_{\mathrm{C}-\mathrm{O}-\mathrm{C}}\right) \mathrm{cm}^{-1}$.

[3]Rotaxane 5. To a solution of a mixture of $2(449 \mathrm{mg}, 0.946$ $\mathrm{mmol})$ and $\mathrm{sec}$-ammonium salt $\mathbf{3}^{50}(345 \mathrm{mg}, 0.860 \mathrm{mmol})$ in $\mathrm{CHCl}_{3}(1.0 \mathrm{~mL})$ was added bis(4-isocyanatophenyl)methane $(108 \mathrm{mg}, 0.430 \mathrm{mmol})$ and di- $n$-butyltin dilaurate (DBTDL, $26.0 \mu \mathrm{L}, 43.0 \mathrm{mmol}$ ) at an ambient temperature. The resulting mixture was stirred for $24 \mathrm{~h}$ and concentrated by evaporation. The resulting residue was dissolved in $\mathrm{CH}_{2} \mathrm{Cl}_{2}(20 \mathrm{~mL})$ and washed with $10 \mathrm{~mL}$ of saturated $\mathrm{NH}_{4} \mathrm{PF}_{6}$ aq. The organic layer was dried over anhydrous $\mathrm{MgSO}_{4}$ and evaporated. The residual solid material was purified by silica gel column chromatography (eluent: $\mathrm{CH}_{2} \mathrm{Cl}_{2}$ and then $\mathrm{CH}_{2} \mathrm{Cl}_{2}-\mathrm{MeOH}(100 / 1, \mathrm{v} / \mathrm{v})$ ) to give [3]rotaxane $\mathbf{5}(741 \mathrm{mg}, 86 \%)$ as a yellow solid. $\mathrm{Mp}$ 134.5-136.6 ${ }^{\circ} \mathrm{C} ;{ }^{1} \mathrm{H}$ NMR (400 MHz, $\left.\mathrm{CDCl}_{3}, 298 \mathrm{~K}\right): \delta 7.44$ (br s, 2H, NH), 7.27 (br, 2H, $\mathrm{NH}_{2}$ ), 7.25 (m, 8H, Ar-H), 6.94 $(\mathrm{m}, 6 \mathrm{H}, \mathrm{Ar}-\mathrm{H}), 6.85-6.60(\mathrm{~m}, 18 \mathrm{H}), 6.50(\mathrm{~m}, 2 \mathrm{H}$, vinyl-H), $5.52(\mathrm{~m}, 2 \mathrm{H}$, vinyl-H), $5.04(\mathrm{~m}, 2 \mathrm{H}$, vinyl-H), 4.96 (s, 4H), 4.54 (m, 4H), $4.36(\mathrm{~m}, 4 \mathrm{H}), 4.09-3.91(\mathrm{~m}, 16 \mathrm{H}), 3.71(\mathrm{~s}, 2 \mathrm{H}), 3.75-$ $3.59(\mathrm{~m}, 16 \mathrm{H}), 3.46-3.29(\mathrm{~m}, 16 \mathrm{H}), 2.05(\mathrm{~s}, 12 \mathrm{H}) \mathrm{ppm}$; ${ }^{13} \mathrm{C}$ NMR $\left(100 \mathrm{MHz}, \mathrm{CDCl}_{3}, 298 \mathrm{~K}\right): \delta 153.45,147.34,147.18$, $138.19,137.56,136.15,136.95,131.32,130.49,129.43$, $129.14,127.79,126.50,121.54,119.87,118.80,112.55$, $112.48,112.35,109.88,70.53,70.04,68.19,68.04,65.71$, 52.50, 52.19, 40.43, $21.07 \mathrm{ppm}$; IR (KBr) 3065 ( $v_{\mathrm{C}-\mathrm{H}}$ vinyl), $1728\left(v_{\mathrm{C}=\mathrm{O}}\right.$ ester $), 843\left(v_{\mathrm{P}-\mathrm{F}}\right), 557\left(v_{\mathrm{P}-\mathrm{F}}\right) \mathrm{cm}^{-1}$; high-resolution mass spectrum, $m / z$ Calcd. for $\mathrm{C}_{101} \mathrm{H}_{122} \mathrm{~N}_{4} \mathrm{O}_{20} \quad[\mathrm{M}]^{+}$ 1710.8652; found: 1710.8649 ;

$\mathrm{N}$-Acetylated [3]Rotaxane 6. A mixture of 5 (356 mg, $0.177 \mathrm{mmol}$ ), acetic anhydride $(72.4 \mathrm{mg}, 0.709 \mathrm{mmol})$, and triethylamine $(179 \mathrm{mg}, 1.77 \mathrm{mmol})$ in dry DMF $(1.4 \mathrm{~mL})$ was stirred at room temperature for $12 \mathrm{~h}$. The mixture was diluted with $\mathrm{CH}_{2} \mathrm{Cl}_{2}(10 \mathrm{~mL})$, washed with $1 \mathrm{M}$ hydrochloric acid and saturated sodium carbonate, and dried over anhydrous $\mathrm{MgSO}_{4}$. The organic layer was evaporated and the resulting crude product was purified by preparative GPC to give $6(225 \mathrm{mg}$, 

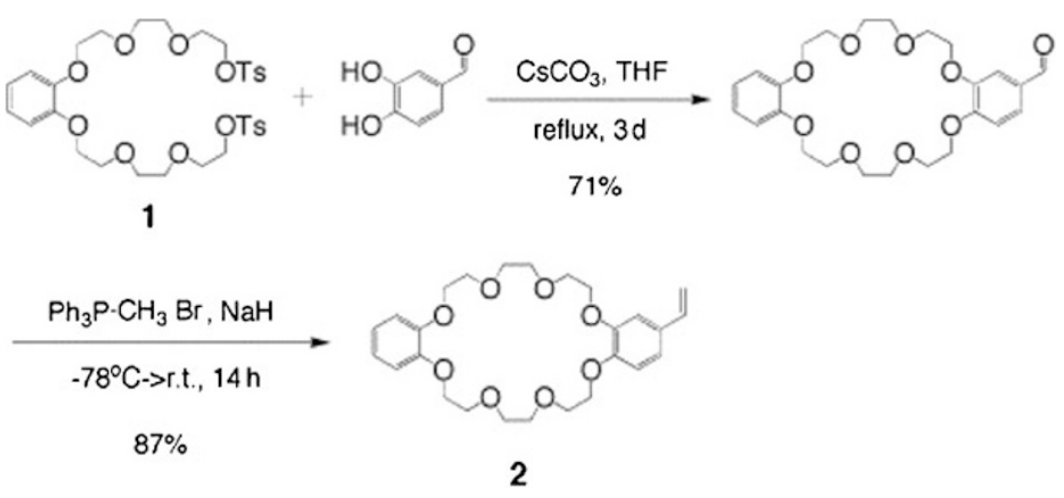

Scheme 1.

$71 \%$ ) as a white solid. Mp 94.4-96.2 ${ }^{\circ} \mathrm{C} ;{ }^{1} \mathrm{H}$ NMR (400 MHz, $\left.\mathrm{CDCl}_{3}, 298 \mathrm{~K}\right) \delta 8.58$ (br s, $\left.2 \mathrm{H}, \mathrm{NH}\right), 7.40$ (m, 8H, Ar-H), 6.98-6.70 (m, 20H, Ar-H), 6.66-6.58 (m, 2H, vinyl-H), $5.55(\mathrm{~s}$, $2 \mathrm{H}), 5.51(\mathrm{~m}, 2 \mathrm{H}$, vinyl-H), $5.10(\mathrm{~m}, 2 \mathrm{H}$, vinyl-H), $4.49(\mathrm{~m}$, $1 \mathrm{H}), 4.44(\mathrm{~m}, 1 \mathrm{H}), 4.28(\mathrm{~m}, 2 \mathrm{H}), 4.10(\mathrm{~m}, 8 \mathrm{H}), 3.82(\mathrm{~m}, 6 \mathrm{H})$, $3.71(\mathrm{~m}, 4 \mathrm{H}), 3.36(\mathrm{~m}, 8 \mathrm{H}), 2.29(\mathrm{~m}, 6 \mathrm{H}), 2.27(\mathrm{~m}, 6 \mathrm{H}), 2.15$ $(\mathrm{m}, 6 \mathrm{H}) \mathrm{ppm} ;{ }^{13} \mathrm{C} \mathrm{NMR}\left(100 \mathrm{MHz}, \mathrm{CDCl}_{3}, 298 \mathrm{~K}\right) \delta 170.98$, $170.85,153.60,148.32,148.29,148.26,148.23,138.42$, $137.94,137.45,137.31,137.12,136.42,136.39,136.28$, $135.25,134.69,134.24,130.38,130.35,129.01,128.92$, $128.87,127.70,127.50,127.41,125.91,125.65,123.89$, $120.61,119.20,118.08,117.98,111.86,111.59,69.56,69.44$, 68.08, 67.97, 67.89, 65.60, 65.49, 50.35, 50.30, 47.58, 40.58, 21.62, 21.60, 21.18, $21.14 \mathrm{ppm}$; IR (KBr) 3065 ( $v_{\mathrm{C}-\mathrm{H}}$ vinyl), $1725\left(v_{\mathrm{C}=\mathrm{O}}\right.$ ester), $1647\left(v_{\mathrm{C}=\mathrm{O}}\right.$ amide) $\mathrm{cm}^{-1}$; high-resolution mass spectrum $m / z$ Calcd. for $\mathrm{C}_{105} \mathrm{H}_{124} \mathrm{~N}_{4} \mathrm{O}_{22} \mathrm{Na}[\mathrm{M}+\mathrm{Na}]^{+}$ 1815.8605; found 1815.8594.

Polymerization (A Typical Procedure). A mixture of 6 (17.9 $\mathrm{mg}, 10.0 \mu \mathrm{mol}), 7 \mathbf{a}(3.30 \mathrm{mg}, 10.0 \mu \mathrm{mol}), \mathrm{Pd}(\mathrm{OAc})_{2}(1.10 \mathrm{mg}$, $5.00 \mu \mathrm{mol})$, tributylamine $(4.7 \mu \mathrm{L})$, and $\mathrm{P}(o \text {-tolyl })_{3}(1.50 \mathrm{mg}$, $5.00 \mu \mathrm{mol})$ was dissolved in $120 \mu \mathrm{L}$ of dry DMF. The mixture was heated at $90^{\circ} \mathrm{C}$ for $48 \mathrm{~h}$ under $\mathrm{Ar}$ atmosphere. The mixture was cooled to room temperature and then precipitated by pouring into methanol $(100 \mathrm{~mL})$. The resulting precipitate was collected by filtration, washed with methanol several times, and dried in vacuo to give poly[3] rotaxane $8 \mathbf{a}(15.1 \mathrm{mg}, 82 \%$ yield). ${ }^{1} \mathrm{H}$ NMR $\left(400 \mathrm{MHz}, \mathrm{CDCl}_{3}, 298 \mathrm{~K}\right) \delta 8.11(\mathrm{~m}, 4 \mathrm{H}, \mathrm{Ar}-\mathrm{H})$, 7.81-7.49 (m, 8H, 7.18-6.58 (m, 14H), $6.00(\mathrm{~s}, 2 \mathrm{H}), 4.52(\mathrm{~m}$, $2 \mathrm{H}), 4.37$ (m, 2H), 4.23-4.04 (m, 8H), 3.86-3.59 (m, 8H), 3.32 (m, 4H), 3.08-2.85 (m, 4H), $2.29(\mathrm{~m}, 6 \mathrm{H}), 2.28(\mathrm{~m}, 6 \mathrm{H}), 2.06$ $(\mathrm{m}, 3 \mathrm{H}) \mathrm{ppm}$; IR $(\mathrm{KBr}) 1710\left(v_{\mathrm{C}=\mathrm{O}}\right.$ ester $), 1647$ ( $v_{\mathrm{C}=\mathrm{O}}$ amide $)$ $\mathrm{cm}^{-1}$. Molecular weight and thermal property of $\mathbf{8}$ are listed in Table I.

\section{RESULTS AND DISCUSSION}

\section{Synthesis of [3]Rotaxane Monomer 6}

Styrenic vinyl-functionalized wheel 2 was prepared in $62 \%$ overall yield by the reaction of an oxyethylene chain-containing ditosylate 1 with 4-formylcathecol to monoformyl dibenzo24-crown-8-ether followed by the conversion of the formyl group to the vinyl group by the Wittig reaction, as shown in Scheme $1 .^{48}$ The structure of $\mathbf{2}$ was determined by the ${ }^{1} \mathrm{H}$ NMR and IR spectra.

Synthesis of [3]rotaxane 6 was carried out according to the urethane end-capping protocol ${ }^{49}$ of intermediary pseudorotaxane 4 formed in situ (Scheme 2). A mixture of vinylfunctionalized crown ether wheel $\mathbf{2}$ and hydroxy-terminated sec-ammonium salt $\mathbf{3}$ was allowed to stand at room temperature to form the threading complex pseudorotaxane 4 . The mixture was then treated with bis(4-isocyanatophenyl)methane as an end-capping agent for two moles of in situ-formed $\mathbf{4}$ in the presence of a catalytic amount of DBTDL (Scheme 2).

Rotaxane 5 was obtained as yellow solid in $86 \%$ isolated yield. Comparison of the ${ }^{1} \mathrm{H}$ NMR spectrum of $\mathbf{5}$ with that of the free components wheel $\mathbf{2}$ and axle $\mathbf{3}$ confirms its interlocked structure, especially from the typical chemical shift changes in ${ }^{1} \mathrm{H}$ NMR where the all signals were assignable (Figure 3 ). The most designating characteristics in the spectra involve the signals of the benzylic protons neighboring the sec-ammonium group of the axle $\left(\mathrm{H}_{\mathrm{d}}\right.$ and $\left.\mathrm{H}_{\mathrm{e}}\right)$, which are largely downfieldshifted (from 3.91, 3.90 ppm to $4.66,4.22 \mathrm{ppm}$ ) by the rotaxanation. The clear downfield shift can be explained by the generation of the $\mathrm{CH}-\mathrm{O}$ interaction of the benzylic protons by the complexation with the crown ether wheel. ${ }^{48-52}$ The methyl proton singal on the phenyl ring of the axle $\left(\mathrm{H}_{\mathrm{a}}\right)$ is shifted to upfield, because of the shielding effect of the benzene ring of the crown ether wheel. Since [3] rotaxane $\mathbf{5}$ is a mixture of two diastereomers based on the lowered symmetry of the wheel $\mathbf{2}$ due to the vinyl substitution, the spectrum of $\mathbf{5}$ is not very simple, as shown in Figure 3.

The treatment of $\mathbf{5}$ with excess amount of triethylamine and acetic anhydride gave $N$-acetylated [3] rotaxane $\mathbf{6}$ in $71 \%$ yield (Scheme 2), in good accordance with the reported result. ${ }^{51,52}$ In the ${ }^{1} \mathrm{H}$ NMR of 6 (Figure 3), the signal of the urethane $O$ benzylic methylene and urethane $\mathrm{NH}$ protons $\left(\mathrm{H}_{\mathrm{h}}\right.$ and $\left.\mathrm{H}_{\mathrm{i}}\right)$ showed a large downfield shift from 4.96 and 7.44 to 5.55 and 8.58 , respectively. This is most indicative of the rotaxane structure, ${ }^{52}$ because of the crown ether moved from being around the ammonium group to the urethane bonding site. Two split signals of the benzylic protons $\left(\mathrm{H}_{\mathrm{d}}\right.$ and $\left.\mathrm{H}_{\mathrm{e}}\right)$ neighboring to the amide nitrogen would be attributed to the syn-anti 


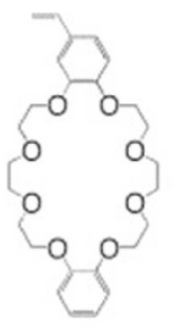

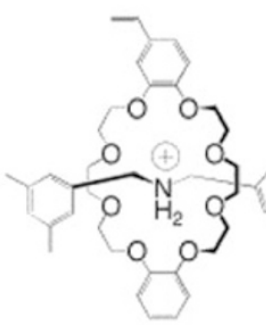

DBTDL. $\mathrm{CH}_{2} \mathrm{Cl}_{2}$, r.t., $12 \mathrm{~h}$ $86 \%$
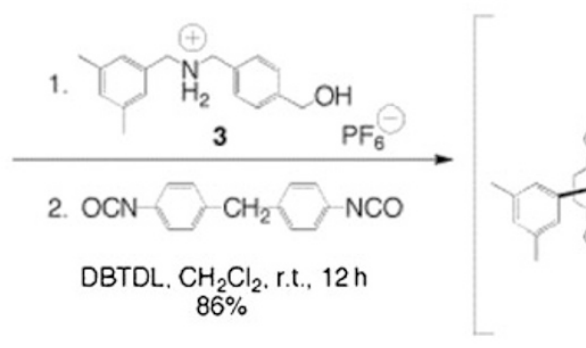

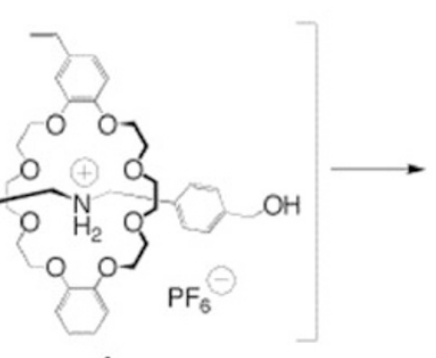

4
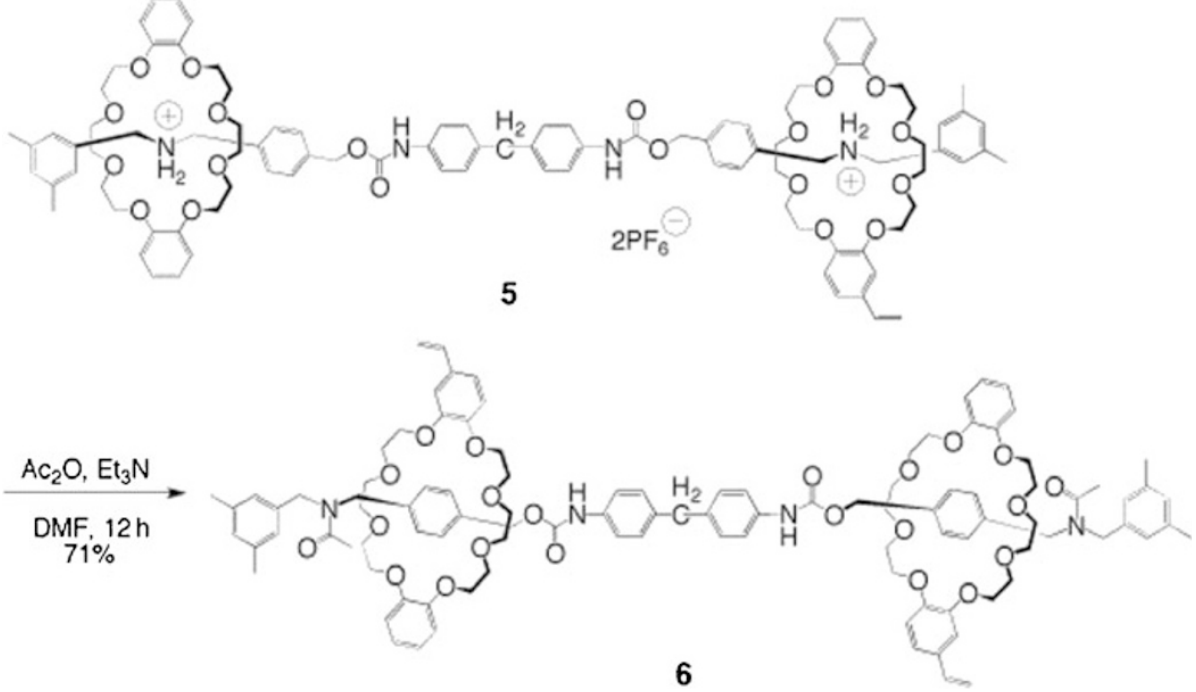

Scheme 2.

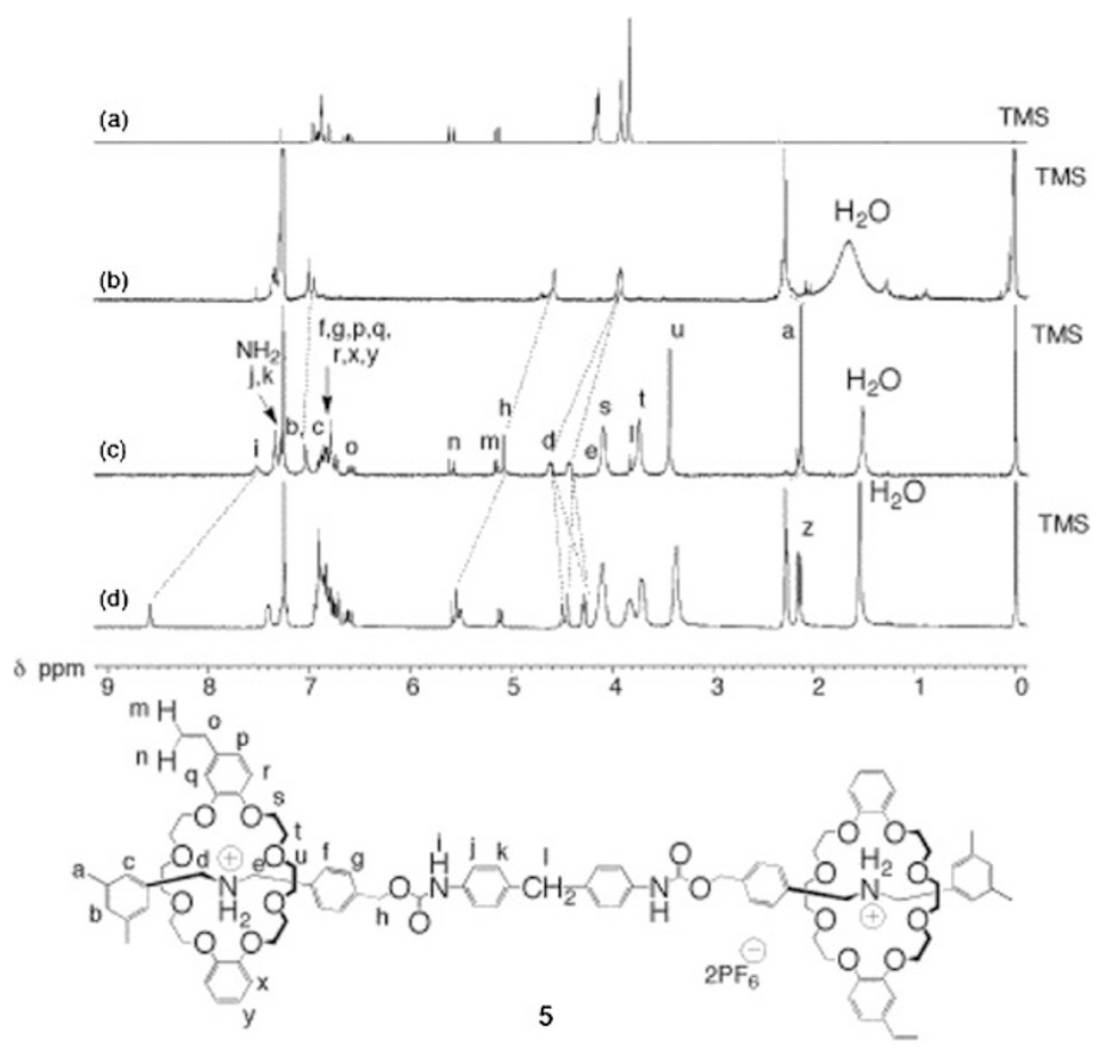

Figure 3. ${ }^{1} \mathrm{H}$ NMR spectra $\left(400 \mathrm{MHz}, \mathrm{CDCl}_{3}, 298 \mathrm{~K}\right.$ ) of (a) wheel component 2, (b) axle component 3, (c) [3]rotaxane 5, and (d) $\mathrm{N}$-acetylated [3]rotaxane 6. The signal $z$ denotes that of $\mathrm{N}$-acetyl methyl protons of 6 . 

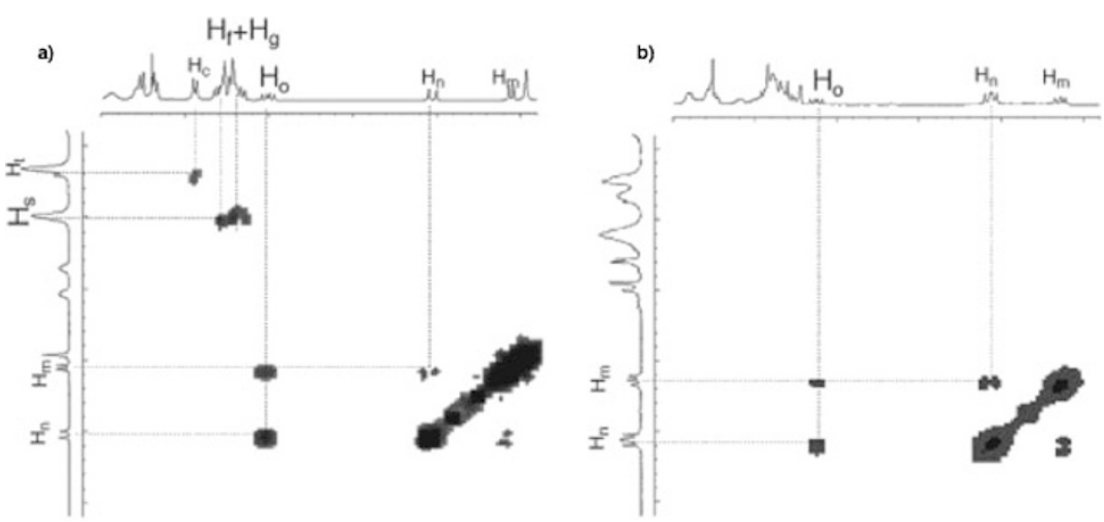

Figure 4. Partial two-dimensional ${ }^{1} \mathrm{H}$ NMR spectra $\left(400 \mathrm{MHz}, \mathrm{CDCl}_{3}, 298 \mathrm{~K}\right)$ of (a) [3]rotaxane 5 and (b) $\mathrm{N}$-acetylated [3]rotaxane 6.

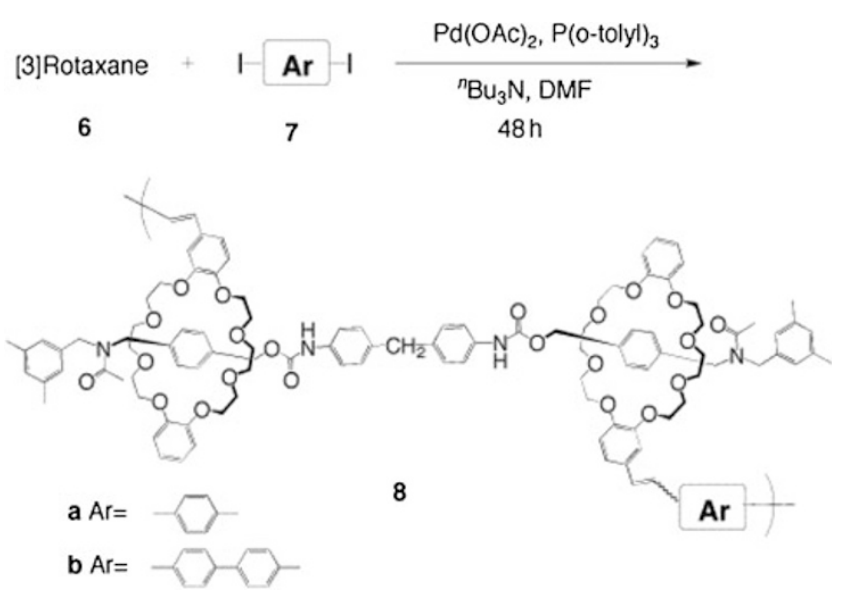

Scheme 3.

stereoisomerism of the amide group formed by the acetylation, but not to the diastereotopic relation caused by the asymmetric nitrogen atom. Thus, all proton signals including vinylic signals other than the aromatic signals of $\mathbf{6}$ are assignable as those of the proposed rotaxane structure.

The mobility of the wheel component on the axle component in the [3] rotaxane $\mathbf{5}$ and $\mathbf{6}$ was examined by painstaking analysis of two-dimensional NOESY ${ }^{1} \mathrm{H}$ NMR spectra (Figure 4). In the case of [3] rotaxane 5, the $\mathrm{H}_{\mathrm{s}}$ and $\mathrm{H}_{\mathrm{t}}$ signals on the wheel component indicated the presence of strong NOEs with $\mathrm{H}_{\mathrm{f}}$ and $\mathrm{H}_{\mathrm{b}}$ in the axle component, respectively, however the $\mathrm{H}_{\mathrm{s}}$ and $\mathrm{H}_{\mathrm{t}}$ on the wheel component of [3] rotaxane $\mathbf{6}$ showed no correlation with other protons. This result suggests that the wheel components of [3] rotaxane $\mathbf{6}$ are freely moving along the axle component, being consistent with the disappearance of the strong attractive interaction between the components by the $N$ acetylation.

\section{Polymerization}

The Mizoroki-Heck coupling ${ }^{53}$ is a widely used carboncarbon bond forming reaction catalyzed by $\operatorname{Pd}(0)$ between aryl halide and olefinic compound in the presence of a hindered amine, and thereby was chosen for the present polymerization.
Table I. Polycondensation of [3] rotaxane 6 with dihaloarene 7 under the Mizoroki-Heck coupling condition ${ }^{a}$

\begin{tabular}{cccccccccccc}
\hline Entry & $\begin{array}{c}\text { Dihalo- } \\
\text { arene }\end{array}$ & $\begin{array}{c}\left({ }^{\circ} \mathrm{C}\right) \\
\text { a }\end{array}$ & Polym. & $\begin{array}{c}\text { Yield } \\
(\%)\end{array}$ & $M_{\mathrm{w}}{ }^{b}$ & $M_{\mathrm{n}}{ }^{b}$ & $M_{\mathrm{w}} / M_{\mathrm{n}}{ }^{b}$ & $\begin{array}{c}T_{\mathrm{g}}{ }^{c} \\
\left({ }^{\circ} \mathrm{C}\right)\end{array}$ & $\begin{array}{c}T_{\mathrm{d} 5}{ }^{d} \\
\left({ }^{\circ} \mathrm{C}\right)\end{array}$ & $\begin{array}{c}T_{\mathrm{d} 10^{d}} \\
\left({ }^{\circ} \mathrm{C}\right)\end{array}$ \\
\hline 1 & $\mathbf{7 a}$ & 90 & $\mathbf{8 a}$ & 82 & 18 & 7.3 & 2.5 & 90 & 247 & 271 \\
2 & $\mathbf{7 a}$ & 60 & $\mathbf{8 a}$ & 40 & 5.6 & 3.9 & 1.4 & - & - & - \\
3 & $\mathbf{7 b}$ & 90 & $\mathbf{8 b}$ & 88 & 14 & 4.4 & 3.1 & 88 & 286 & 308 \\
4 & $\mathbf{7 b}$ & 60 & $\mathbf{8 a}$ & 34 & 3.4 & 2.6 & 1.3 & - & - & - \\
\hline
\end{tabular}

a Polymerization conditions: [[3]rotaxane 6] $=$ [dihaloarene 7] $=0.1 \mathrm{M}$, $48 \mathrm{~h}$, in DMF. ${ }^{b}$ Determined by GPC $\left(\mathrm{CHCl}_{3}\right.$, polystyrene standards). ${ }^{c}$ Glass transition temperature obtained by DSC at a heating rate of $10^{\circ} \mathrm{C} /$ min under nitrogen $\left(\mathrm{N}_{2}\right.$ flow rate: $50 \mathrm{~mL} / \mathrm{min}$ ) in the second scan. ${ }^{d} 5 \%$ Weight loss temperature obtained by TGA at a heating rate of $10^{\circ} \mathrm{C} / \mathrm{min}$ under nitrogen ( $\mathrm{N}_{2}$ flow rate: $50 \mathrm{~mL} / \mathrm{min}$ ).

Poly[3]rotaxane $\mathbf{8}$ was obtained by the polycondensation through the $\mathrm{Pd}(0)$-catalyzed coupling of $\mathrm{N}$-acetylated [3]rotaxane monomer 6 and diiodoarene 7 in DMF for $48 \mathrm{~h}$ in the present of ${ }^{\mathrm{n}} \mathrm{Bu}_{3} \mathrm{~N}$ (Scheme 3). The results are summarized in Table I. Polymers $\mathbf{8 a}$ and $\mathbf{8 b}$ were obtained as solid in $80 \%$ and $88 \%$ yields, respectively, under the polymerization at $90{ }^{\circ} \mathrm{C}$. However, the polymerization at $60^{\circ} \mathrm{C}$ afforded only low molecular weight polymers in low yields. Each of $\mathbf{8}$ had a unimodal GPC profile showing the molecular weight $M_{\mathrm{w}}$ $14,000(\mathbf{8 a})$ and $18,000(\mathbf{8 b})$ with the molecular weight distribution of 2.5 and 3.1, respectively.

The structure of 8 was characterized by IR and ${ }^{1} \mathrm{H}$ NMR spectra in addition to the GPC result. FT-IR spectra showed the characteristic absorption peak of the vinyl group at $3065 \mathrm{~cm}^{-1}$ which largely decreased after the polymerization. At the same time, a weak absorption peak at $961 \mathrm{~cm}^{-1}$ corresponding to the out-plane bending made of the trans-vinylene groups appeared, suggesting that the generated vinylene group takes mainly trans configuration. ${ }^{54}$ The ${ }^{1} \mathrm{H}$ NMR spectrum (Figure 5) is quite similar to that of rotaxane monomer $\mathbf{6}$ except for the aromatic and vinyl signals, although most signals are broadened. Small vinylic methylene signals $\mathrm{H}_{m}$ and $\mathrm{H}_{n}$ appeared around 5.51 and $5.10 \mathrm{ppm}$, respectively, were attributed to those of the vinyl group of polymer terminal end, which significantly decreased as the polymerization progressed. Detailed information on the degree of polymerization (DPs) was obtained by the end group analysis of the ${ }^{1} \mathrm{H}$ NMR 


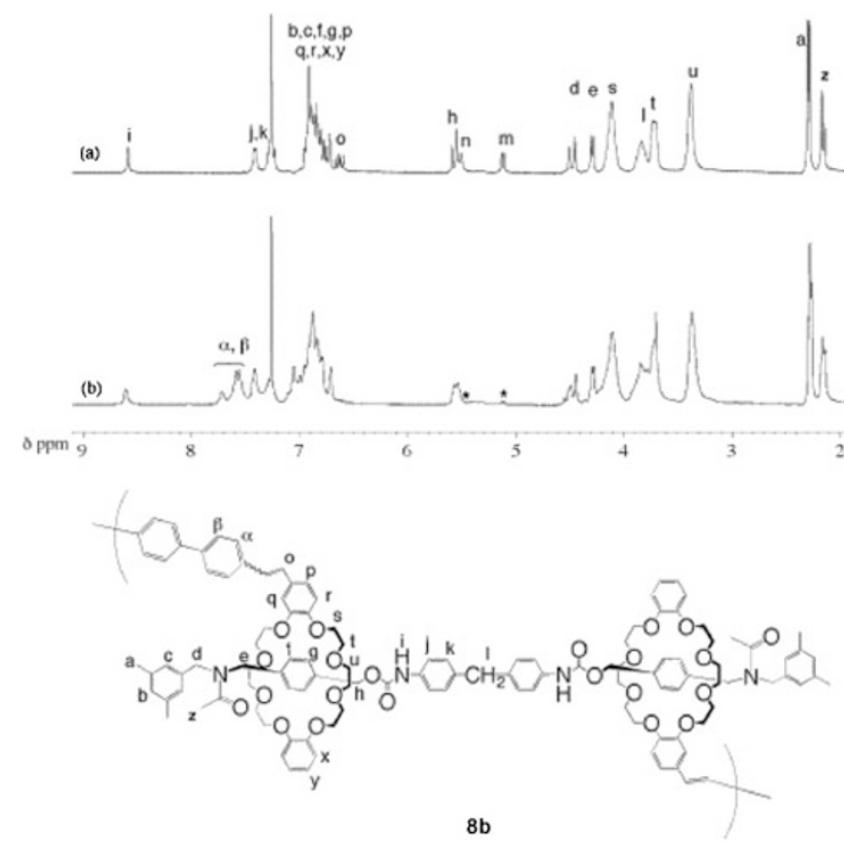

Figure 5. Partial ${ }^{1} \mathrm{H}$ NMR spectra $\left(400 \mathrm{MHz}, \mathrm{CDCl}_{3}, 298 \mathrm{~K}\right)$ of (a) [3]rotaxane 6 and (b) poly[3]rotaxane $8 \mathrm{~b}$. The signals $*$ around 5.6 and $5.1 \mathrm{ppm}$ denote the terminal vinyl proton signals of the polymer chain.

spectrum (Figure 5). The signal integration of the terminal vinyl protons (5.54 and $5.10 \mathrm{ppm}$ ) was compared with that of the methyl protons (2.29 aand $2.27 \mathrm{ppm}$ ) of the end-capping groups. As a result, the averaged DPs of $\mathbf{8 a}$ and $\mathbf{8 b}$ were estimated to be DP 8.0 and 5.4, which corresponded to the $M_{\mathrm{n}}$ value of 7,500 and 5,200, respectively, being comparable with the GPC data of $M_{\mathrm{n}} 7,300$ and 4,400, respectively (Table I).

\section{Properties of Poly[3]rotaxane 8}

Both poly[3]rotaxanes $\mathbf{8 a}$ and $\mathbf{8 b}$ were soluble in ordinary organic solvents such as dichloromethane, chloroform, and THF, but insoluble in methanol and $n$-hexane. Based on their high solubility, transparent polymer films could be prepared on a glass by casting from their chloroform solution, although no strong self-standing film was obtained, probably due to the low degree of polymerization.

Thermal properties of $\mathbf{8}$ were evaluated by TGA and DSC (Table I). Good thermal stability was confirmed from the weight loss temperatures at 247 and $286{ }^{\circ} \mathrm{C}$ (5\% weight loss) for $\mathbf{8 a}$ and $\mathbf{8 b}$, respectively. Thermal events around the temperature of 90 and $88^{\circ} \mathrm{C}$ range as observed by DSC during the heating scans could be attributed to the glass transitions $\left(T_{\mathrm{g}}\right)$.

Thus, this paper has demonstrated the synthesis of divinyl [3] rotaxane monomer and its derivation to poly[3] rotaxanes 8 possessing the rotaxanated polymacrocycle structure in the main chain according to the rotaxanation-polymerization protocol. The polyrotaxane is categorized as one of the polymers having no successive covalent bond in the polymer main chain. The polymerization was carried out by the poly(Mizoroki-Heck coupling) of styrenic vinyl-functionalized wheel-containing [3] rotaxane 6 with dihaloarenens 7 such as diiodoarenes in the presence of a catalytic amount of $\mathrm{Pd}(\mathrm{OAc})_{2}$ to yield poly(phenylene-vinylene)-type polymers $\mathbf{8}$. The mainchain type poly[3]rotaxanes $\mathbf{8}$ obtained in high yields showed a molecular weight range of $M_{\mathrm{w}} 14,000-18,000\left(M_{\mathrm{n}} 4,400\right.$ $7,300)$ with molecular weight distributions of 2.5-3.1, whereas film-forming property based on their good solubility in ordinary organic solvents was confirmed, in addition to their good thermal stability. The present successful synthesis of the main chain-type polyrotaxanes based on the rotaxanationpolymerization protocol provides an efficient entry to polyrotaxanes, since this method suggests the possibility of preparing the main chain-type polyrotaxanes possessing many type of backbones by the polycondensation without the application of thermodynamic process.

Received: November 16, 2008

Accepted: February 3, 2009

Published: April 15, 2009

\section{REFERENCES}

1. H. W. Gibson, M. C. Bheda, and P. T. Engen, Prog. Polym. Sci., 19, 843 (1994).

2. F. Vögtle, T. Dunnwald, and T. Schmidt, Acc. Chem. Res., 29, 451 (1996).

3. H. W. Gibson, in "Large Ring Molecules" Semlyen, J. A. Semlyen, Ed., John Wiley and Sons: New York, 1996, chapt. 6, p 191.

4. M. C. T. Fyfe and J. F. Stoddart, Acc. Chem. Res., 30, 393 (1997).

5. A. Harada, Adv. Polym. Sci., 133, 141 (1997).

6. S. A. Nepogodiev and J. F. Stoddart, Chem. Rev., 98, 1959 (1998).

7. "Molecular Catenanes, Rotaxanes, and Knots," J.-P. Sauvage and C. Dietrich-Buchecker, Ed., Wiley-VCH, Weinheim, 1999.

8. F. M. Raymo and J. F. Stoddart, Chem. Rev., 99, 1643 (1999).

9. T. Takata and N. Kihara, Rev. Heteroat. Chem., 22, 197 (2000).

10. E. Mahan and H. W. Gibson, in "Cyclic polymers," 2nd ed, E. R. Semlyen, Ed., Kluwer Publishers, Dordrecht, 2000, p 415.

11. T. J. Hubin and D. H. Busch, Coord. Chem. Rev., 200, 5 (2000).

12. A. Harada, Acc. Chem. Res., 34, 456 (2001).

13. I. G. Panova and I. N. Tocpchieva, Russ. Chem. Rev., 70, 23 (2001).

14. T. Takata, N. Kihara, and Y. Furusho, Adv. Polym. Sci., 171, 1 (2005).

15. F. Huang and H. W. Gibson, Prog. Polym. Sci., 30, 982 (2005).

16. S. J. Cantrill, K. S. Chichak, A. J. Peters, and J. F. Stoddart, Acc. Chem. Res., 38, 1 (2005).

17. G. Wenz, B.-H. Han, and A. Müller, Chem. Rev., 106, 782 (2006).

18. T. Takata, Polym. J., 38, 1 (2006).

19. R. Liu, A. Harada, and T. Takata, Polym. J., 39, 1, 21 (2007).

20. K. Ito, Polym. J., 39, 6, 489 (2007).

21. P. Ashton, I. Baxter, S. J. Cantrill, M. C. T. Fyfe, P. T. Glink, J. F. Stoddart, A. J. P. White, and D. J. Williams, Angew. Chem., Int. Ed., 37, 1294 (1998).

22. P. R. Ashton, I. W. Parsons, F. M. Raymo, J. F. Stoddart, A. J. P. White, D. J. Williams, and R. Wolf, Angew. Chem., Int. Ed., 37, 1913 (1998).

23. N. Yamaguchi and H. W. Gibson, Angew. Chem., Int. Ed., 38, 143 (1999).

24. S. J. Rowan, S. J. Cantrill, J. F. Stoddart, A. J. P. White, and D. J. Williams, Org. Lett., 2, 759 (2000).

25. T. Fujimoto, Y. Sakata, and T. Kaneda, Chem. Commun., 2143 (2000).

26. T. Hoshino, M. Miyauchi, Y. Kawaguchi, H. Yamaguchi, and A. Harada, J. Am. Chem. Soc., 122, 9876 (2000). 
27. H. Onagi, C. J. Easton, and S. F. Lincoln, Org. Lett., 3, 1041 (2001).

28. S. J. Rowan and J. F. Stoddart, Polym. Adv. Technol., 13, 777 (2002).

29. Y. Hasegawa, M. Miyauchi, Y. Takashima, H. Yamaguchi, and A. Harada, Macromolecules, 38, 3724 (2005).

30. M. Miyauchi, T. Hoshino, H. Yamaguchi, S. Kamitori, and A. Harada, J. Am. Chem. Soc., 127, 2034 (2005).

31. M. Miyauchi, Y. Takashima, H. Yamaguchi, and A. Harada, J. Am. Chem. Soc., 127, 2984 (2005).

32. A. Harada, J. Polym. Sci., Part A: Polym. Chem., 44, 5113 (2006).

33. T. Sato and T. Takata, Macromolecules, 41, 2739 (2008).

34. T. Oku, Y. Furusho, and T. Takata, J. Polym. Sci., Part A: Polym. Chem., 41, 119 (2003).

35. Y. Sohgawa, H. Fujimori, J. Shoji, Y. Furusho, N. Kihara, and T. Takata, Chem. Lett., 30, 774 (2001).

36. Y. Geerts, D. Muscat, and K. Müllen, Macromol. Chem. Phys., 196, 3425 (1995).

37. J. L. Weidmann, J.-M. Kern, J.-P. Sauvage, Y. Geerts, D. Muscat, and K. Müllen, Chem. Commun., 1243 (1996).

38. D. Muscat, A. Witte, W. Köhler, K. Müllen, and Y. Geerts, Macromol. Rapid. Commun., 18, 233 (1997).

39. S. Menzer, A. J. P. White, D. J. Williams, M. Belohradsky, C. Hamers, F. M. Raymo, A. N. Shipway, and J. F. Stoddart, Macromolecules, 31, 295 (1998).

40. C. Hamers, F. M. Raymo, and J. F. Stoddart, Eur. J. Org. Chem., 2109 (1998).

41. J. L. Weidmann, J.-M. Kern, J.-P. Sauvage, D. Muscat, S. Mullins, W.
Köhler, C. Rosenauer, H. J. Räder, K. Martin, and Y. Geerts, Chem. Eur. J., 5, 1841 (1999).

42. D. Muscat, W. Köhler, H. J. Räder, K. Martin, S. Mullins, B. Müller, K. Müllen, and Y. Geerts, Macromolecules, 32, 1737 (1999).

43. S. Shimada, K. Ishikawa, and N. Tamaoki, Acta. Chem. Scand., 52, 374 (1998).

44. C. Hamers, O. Kocian, F. M. Raymo, and J. F. Stoddart, Adv. Mater., 10, 1366 (1998).

45. D. L. Simone and T. M. Swager, J. Am. Chem. Soc., 122, 9300 (2000).

46. C. A. Fustin, C. Bailly, G. J. Clarkson, P. De Groote, T. H. Galow, D. A. Leigh, D. Robertson, A. M. Z. Slawin, and J. K. Y. Wong, J. Am. Chem. Soc., 125, 2200 (2003).

47. H. Sasabe, N. Inomoto, N. Kihara, Y. Suzuki, A. Ogawa, and T. Takata, J. Polym. Sci., Part A: Polym. Chem., 45, 4154 (2007).

48. T. Sato and T. Takata, Tetrahedron Lett., 48, 2797 (2007).

49. Y. Furusho, H. Sasabe, D. Natsui, K. Murakawa, T. Takata, and A. Harada, Bull. Chem. Soc. Jpn., 77, 179 (2004).

50. H. Kawasaki, N. Kihara, and T. Takata, Chem. Lett., 28, 223 (1999).

51. N. Kihara, Y. Tachibana, H. Kawasaki, and T. Takata, Chem. Lett., 29, 506 (2000).

52. Y. Tachibana, H. Kawasaki, N. Kihara, and T. Takata, J. Org. Chem., 71, 5093 (2006).

53. Y. Lee, Y. Liang, and L. Yu, Synlett, 2879 (2006).

54. Y. Liu, C. Yang, Y. Li, Y. Li, S. Wang, J. Zhuang, H. Liu, N. Wang, X. He, Y. Li, and D. Zhu, Macromolecules, 38, 716 (2005). 